\title{
LA REAL EXPEDICIÓN BOTÁNICA A NUEVA ESPAÑA Y LOS INTENTOS DE CREACIÓN DEL JARDÍN BOTÁNICO DE LA HABANA
}

\section{Mercedes Valero}

\section{RESUMEN}

\begin{abstract}
La formación de un Jardín Botánico en La Habana, a principios del siglo XIX, se debió a las esfuerzos de la Real Sociedad Patriótica de La Habana y conjuntamente con los de Martín Sessé en 1795, miembro de la Expedición Botánica a Nueva España, que fue comisionado para el reconocimiento de las producciones naturales y la organización de estudios botánicos y jardines en las colonias. La llegada de Sessé despertó el interés de algunos miembros de la Real Sociedad Patriótica con respecto a la proposición hecha en 1793. Años más tarde, el jardín habanero fue una realidad.
\end{abstract}

\section{SUMMARY}

The creation of a Botanical Garden in La Habana, at the beginning of the nineteenth century, was due to the efforts of teh Real Sociedad Patriótica of La Havana and those of Martín de Sessé in 1795, member of the Botanical Expedition to Nueva España, who was commisioner for the recognition of natural 


\title{
MERCEDES VALERO
}

\begin{abstract}
productions and the organization of botanical studies and gardens at the colonies. The arriving of Sessé awaken the interest of some members of the Real Sociedad Patriótica with respect to the proposition made in 1793. A few years later, the Havanan Garden was a reality.
\end{abstract}

El Jardín Botánico de La Habana, fue una de las principales instituciones científicas creadas en Cuba en el siglo XIX, como resultado de una serie de iniciativas que expresaban en gran medida la política reformista hispánica encaminada al fortalecimiento económico y político de la metrópoli.

En el amplio programa aplicado por España, dado su carácter ilustrado, ocupó la ciencia un importante papel; muestra de ello, fue la organización de expediciones a las posesiones coloniales, que no sólo pretendían la búsqueda y explotación de los recursos naturales, sino que a su vez estimulaban el estudio de algunas ramas de las ciencias, como la botánica y la química, por su utilidad para el fomento de esenciales actividades económicas, como es el caso de la agricultura y la medicina.

En Cuba, este movimiento, dirigido al logro de transformaciones económico-sociales, se hizo sentir a través de dos instituciones: la Sociedad Patriótica de La Habana y el Real Consulado de Agricultura, Industria y Comercio de La Habana, las cuales promovieron desde el propio momento de su creación interesantes ideas encaminadas en este sentido, siendo una de ellas la organización de un Jardín Botánico con su correspondiente Cátedra, por lo que al estudiar los antecedentes de la creación del Jardín Botánico se hace necesario centrar la atención en la labor desarrollada por ambas instituciones, así como la participación que tuvo en la conformación de este proyecto la Sección dependiente de la Expedición Botánica a Nueva España, presente en la Isla entre 1795 y 1798. La mencionada sección, formaba parte del grupo expedicionario que llevó a cabo la citada y estudiada expedición ${ }^{1}$ al territorio mexicano (17871803), dirigida por el médico aragonés Martín de Sessé quien en 1785,

1 Puig-Samper, M. A.; Maldonado, J. L. (1991), "La expedición de Sessé en Cuba y Puerto Rico". Asclepio. Revista de Historia de la Medicina y de la Ciencia, vol. XLIII, fascículo 2, pp. 181-198. Zamudio, G. (1992), «El Jardín Botánico de la Nueva España y la Institucionalización de la Botánica en México». En: «Los Orígenes de la Ciencia Nacional». Cuadernos de Quipu, n. ${ }^{\circ}$ 4, pp. 55-98. ArIAs Drvto, J. E. (1989), Las expediciones científicas españolas durante el siglo XVIIII. Expedición botánica de Nueva España. Madrid. 
solicitó desde La Habana, - donde se encontraba como cirujano en la escuadra del Marqués de Socorro-, la aprobación de las autoridades españolas para realizar tal empresa. Los objetivos bien definidos en su solicitud, se orientaban al inventario y descripción de las producciones naturales de este virreinato, así como la formación de un Jardín Botánico que constituyera centro de las actividades desarrolladas por los expedicionarios y contara con una Cátedra de Botánica para el ejercicio de la enseñanza de esta disciplina, como complemento de los estudios médicos y farmacéuticos, facilitando la aplicación de las reformas de estas profesiones.

Este proyecto fue aprobado por Real Orden en octubre de $1786^{2}$ y en el mismo tuvieron una importante influencia las gestiones del director del Real Jardín Botánico de Madrid, Casimiro Gómez Ortega (17411818), quien al frente de esta institución desarrolló una brillante labor como promotor del plan de exploración de las colonias españolas. Fue precisamente a él, a quien se debió la elaboración de los documentos legales que regirían el desarrollo de la expedición, entre ellos la redacción de las instrucciones para la remisión de los materiales recolectados a la península, así como la preparación del personal que lo ejecutaría, dada su condición de primer catedrático del Jardín Botánico.

En este sentido, fue designado el grupo expedicionario con sus correspondientes títulos acreditativos e indicaciones pertinentes, compuesto por Martín de Sessé como director de la expedición y el Jardín; Vicente Cervantes como catedrático de botánica; José Longinos Martínez, naturalista; Juan del Castillo y Jaime Senseve como botánicos, a los que posteriormente se les unirían los dibujantes mexicanos Vicente de la Cerda y Atanasio Echevarría ${ }^{3}$.

En 1787 fueron iniciadas las actividades por parte de esta comisión en el territorio mexicano, las que permitieron en un período de un año que fuera inaugurado el Jardín y la Cátedra, de la que se hizo cargo, como ya se ha indicado, Vicente Cervantes, mientras, que por su parte el resto del equipo se consagraba al trabajo de campo en medio de innumerables dificultades, para la recolección de especies de los tres reinos de la naturaleza e inventario y clasificación con vistas a su envío a la

\footnotetext{
${ }^{2}$ Real Resolución de 13 de marzo de 1787. Archivo del Museo Nacional de Ciencias Naturales, Exp. Bot. a N. E.

${ }^{3}$ Real Orden de 13 de marzo de 1787.

Asclepio-Vol. XLVII-2-1995 
península ${ }^{4}$. En tales circunstancias, era imposible para Sessé y sus compañeros explorar todo el virreinato en el tiempo previsto, a pesar de haber adoptado la estrategia de organizarse en equipos que trabajaban de manera simultánea en diferentes puntos; por ello en 1794, fue solicitada por este grupo expedicionario una prórroga de dos años para además reconocer el reino de Guatemala y las islas de Cuba, Santo Domingo y Puerto Rico. La aprobación por parte de las autoridades españolas no se hizo esperar y rápidamente se comenzó la ejecución del nuevo plan, dividiéndose la Comisión en dos grupos: uno de ellos dirigido por el propio director e integrado por el farmacéutico y disecador Jaime Senseve y el pintor Atanasio Echavarría, que a bordo de la fragata Santa Agueda partió desde Veracruz hacia la isla de Cuba el 5 de mayo de 1795, arribando a la Habana el día 31 de ese propio mes ${ }^{5}$.

$\mathrm{Al}$ parecer, el objetivo fundamental de este grupo expedicionario por el momento se centraba en el reconocimiento y exploración del territorio cubano. A pesar de no presentar Cuba el nivel de desarrollo que tenían otras posesiones coloniales, como por ejemplo México, esta Comisión a su llegada encontró que ya existía en la isla un determinado interés por parte de un sector de la naciente clase burguesa hacia el desarrollo de algunas ciencias, como la botánica y la química por su importante aplicación a la medicina y la agricultura y especialmente en el proceso de elaboración del azúcar. Este sector originado como resultado del incremento acelerado de la economía de plantación en la Isla, se encontraba nucleado en la Sociedad Patriótica de la Habana, institución que constituyó centro de activa promoción para el desarrollo de la educación públi$\mathrm{ca}$, la industria y la agricultura creando toda una serie de mecanismos orientados a elevar el comercio; todo ello explica que estuviera dicha Sociedad «siempre abierta a las ventajas que se pudieran obtener en bien del país» ${ }^{6}$. Al conocer esta Institución la presencia en la Isla de Sessé y sus compañeros, se dio a la tarea de contactar con el director de la expedición a través de Nicolás Calvo de la Puerta y O’Farrill — profesor universitario y censor de la institución- a fin de que éste solicitara asesoramiento en relación con algunas plantas para enriquecer un Diccionario

\footnotetext{
${ }^{4}$ Maldonado Polo, J. L. (1987), «El Jardín Botánico de México y la Cátedra de Botánica». En: La Real Expedición Botánica a Nueva España (1787-1803). Madrid, pp. $165-168$

${ }_{6}^{5}$ Puig-Samper, M. A. y Maldonado, J. L. (1991), p. 184.

${ }^{6}$ López SÁnchez, J. (1980), Tomás Romay: escenario histórico. La Habana, p. 21.
} 


\section{LA REAL EXPEDICIÓN BOTÁNICA A NUEVA ESPAÑA}

de voces provinciales que estaba elaborando el mercedario y miembro de la sociedad Fray José María Peñalver; asimismo procuró obtener de Sessé instrucciones para la creación de un Jardín Botánico que se pretendía establecer en la Habana ${ }^{7}$.

En efecto, desde 1793 se había analizado en la Sociedad Patriótica, por parte de Nicolás Calvo de la Puerta la necesidad de crear establecimientos de química y botánica, así como una escuela de agricultura donde además de estudiar las producciones naturales, poder mostrar a los extranjeros los ejemplares de la flora del país y contribuir a su vez al ornato de la ciudad.

En el mes de mayo de ese propio año el botánico francés Pedro Le Compte y Veré, comisionado por el Real Jardín Botánico de Madrid, presentó ante esta Sociedad una memoria relativa al establecimiento de un Jardín Botánico y una escuela; idea que fue acogida con satisfacción, según lo expresado por el doctor Tomás Romay:

Y nos presenta un Profesor de Botánica correspondiente del Real Jardín Botánico de Madrid, como el más apto para establecer otro en esta ciudad, y descubrirnos las virtudes de los vegetales indígenas, concedidos con tanta profusión que de ningún exótico necesitamos ${ }^{8}$.

Le Compte venía trabajando hacía algún tiempo, junto a Mariano Espinosa, cirujano del Regimiento de Caballería de la Habana y corresponsal también del Real Jardín Botánico de Madrid. Los conocimientos del primero y el entusiasmo del segundo se conjugaron para lograr este propósito, salvando así circunstanciales diferencias entre ellos; no obstante Espinosa tuvo que hacerse cargo del "proyecto botánico» por la inesperada muerte del francés el 13 de julio de $1793^{\circ}$.

Durante los meses de noviembre y diciembre Espinosa insistió ante la Sociedad Patriótica para que fuera valorado su nuevo proyecto, pro-

\footnotetext{
${ }^{7}$ Estévez, J. (1951), Trabajos científicos. Apuntes biográficos y recopilación de Luis $F$. Le Roy y Gálvez. La Habana.

${ }^{8}$ Romay, T. (1849), Elogio del Excmo. Sr. D. Luis de las Casas. Memorias de la Sociedad Económica de Amigos del País. La Habana, t. 37, p. 230.

9 VAlero GonZÁlez, Mercedes (1989), «El Jardín Botánico de la Habana en el siglo XIX». Anuario 1, Centro de Estudios de Historia y Organización de la Ciencia. La Habana, p. 250 .
}

Asclepio-Vol. XLVII-2-1995 
poniendo para la ubicación del Jardín los terrenos colindantes a la Casa de la Beneficiencia con su plano correspondiente. Al parecer durante el año la Sociedad Patriótica no prestó la debida atención a la propuesta de Espinosa; pero él continuaba en su empeño, para lo cual solicitó el apoyo del Real Jardín Botánico de Madrid, logrando que a través de algunas gestiones del intendente se le entregara un terreno para iniciar la obra. Este terreno no reunía las condiciones necesarias y lo más que pudo hacer fue sembrar algunos ejemplares que no dieron resultado, por lo desfavorable del lugar ${ }^{10}$.

En realidad, a pesar de que Espinosa pudo contar en algún que otro momento con el apoyo de Casimiro Gómez de Ortega, su anhelado sueño no se pudo concretar; sin embargo esto no impidió que él mismo continuara con la remisión de semillas y plantas al Jardín madrileño en su carácter de corresponsal.

La presencia de la Comisión expedicionaria en la Isla despertó nuevamente el interés por el asunto, al ponerse en consideración de Sessé el proyecto de Mariano Espinosa.

Sessé accedió con beneplácito a facilitar su experiencia, precisamente porque coincidía esta solicitud con uno de los objetivos trazados por la Expedición, ofreciéndose para enseñar botánica a la persona que designase la Sociedad, y que además le acompañaría en el recorrido planificado por el grupo expedicionario. Al reconocer la Sociedad la oportunidad que se le brindaba de iniciar con ello el estudio de esta disciplina, comisionó a Joaquín Herrera y Tomás Romay, para que realizaran la más conveniente selección e informaran al Cuerpo Patriótico ${ }^{11}$.

A través de este informe se presentaba al joven José Estévez y Cantal, distinguido discípulo de Romay, quien poseía conocimientos de medicina y farmacia, así como predisposición para la botánica, condiciones indispensables para este estudio ya que según se indicaba:

No se trata de aprender únicamente las virtudes de las plantas conocidas, sino también de enriquecer, experimentar, clasificar y hacer la nomenclatura de otras muchas ignoradas por Tournefort, y desconocidas al inmortal Linneo. Solicítase quién pueda sustituir a los vegetales exóti-

10 Estévez, J. (1951), pp. 200-201. Ibidem.

11 Archivo Nacional de Cuba (ANC). Junta de Fomento. Legajo 97, Folio 50-56. 


\section{LA REAL EXPEDICIÓN BOTÁNICA A NUEVA ESPAÑA}

cos secos y enervados de que hacemos uso en nuestras dolencias, otros indígenas recientes y proporcionados a nuestra constitución ${ }^{12}$.

Asimismo, en este propio informe fue expuesto que el terreno propuesto por Espinosa, después de un análisis realizado por Sessé se había considerado no apropiado para establecer el Jardín, no sólo por la resequedad de sus suelos sino por estar muy alejado de la ciudad, lo que dificultaba la concurrencia a las clases de botánica ${ }^{13}$. De esta forma se desaprobaba parcialmente el proyecto de Espinosa lo que prácticamente, obligaba a la formulación de un nuevo plan y por ende a la localización de un nuevo terreno para este fin. Al parecer Sessé incorporó esta tarea entre sus gestiones, pronunciándose al efecto posteriormente, pero por el momento se dedicaba a los preparativos del viaje y a la definición en cuanto al financiamiento de Estévez para su incorporación a la expedición.

Al no contar la Sociedad con los fondos necesarios para apoyar la participación de Estévez, solicita el concurso del Real Consulado, el cual en Junta de Gobierno de 7 de diciembre de 1795 acordó:

... considerando la utilidad y sugerencia de la propuesta que se ha hecho por la Real Sociedad, se admite en todas sus partes, destinando de sus fondos la cantidad de mil pesos para que Don José Estévez acompañe a Martín Sessé y aprenda con él la Botánica ${ }^{14}$.

Ello muestra que el Real Consulado, al colaborar en la formación de Estévez con la Real Sociedad, también estaba interesado en la institucionalización de la enseñanza de la botánica en el país, mediante la creación de un jardín. Sessé, por su parte, ultimó los detalles del costo de los estudios de Estévez con esta corporación, comunicando además los pormenores del recorrido que pretendían realizar en compañía de este joven criollo, que incluía las islas de Puerto Rico, Santo Domingo, Trinidad y de ser posible Jamaica ${ }^{15}$.

\footnotetext{
12 Ibidem.

13 Ibidem.

14 Ibidem.

15 Ibidem.
} 


\section{MERCEDES VALERO}

Por su parte, el grupo expedicionario realizaba algunas actividades de investigación ictiológica en las afueras de la ciudad de La Habana, y alguna que otra recolección de especies botánicas ${ }^{16}$.

A principios de marzo de 1797 partió el pequeño grupo hacia Puerto Rico, en la Fragata Gloria, efectuando una vez allí el reconocimiento de la Isla, obstaculizándose la continuidad hacia Santo Domingo con la sublevación de los negros y el estallido de la guerra contra Inglaterra, razones por las que deciden regresar a Cuba, logrando al fin después de algunos inconvenientes arribar a La Habana el 1 de junio de ese propio año.

Una vez en La Habana, Sessé se reúne con la Comisión dirigida por el Conde de Mopox que había llegado a la Isla el 3 de febrero de 1797 con el objetivo de desarrollar un amplio proyecto de diversas actividades, entre ellas las científicas. Esta Comisión pretendía la recolección e inventario de especies botánicas, lo que explica que entre sus participantes se encontrara el botánico Manuel Baltasar Boldo y el dibujante y disecador José Guío ${ }^{17}$.

Del encuentro entre ambos grupos y debido a la afinidad de intereses, surge la idea de un trabajo conjunto. De inmediato Sessé informa a la Junta del Real Consulado su decisión de que Estévez participe en este nuevo proyecto, argumentando que:

Su buen talento y aplicación le han granjeado los conocimientos necesarios por sí mismo, y a costa de algún ejercicio poder formar un perfecto profesor capaz de cualquier observación, y de enseñar la ciencia sobre los mismos principios. Acabaría de disponerse por este Estado de Perfección si me acompañase en el viaje que voy a emprender por la parte occidental de esta Isla, asociado a don Baltasar Boldo primer botánico de la expedición científica de el Señor Conde de Santa Cruz de Mopox, á que no será difícil, y convendría agregarle con satisfacción de los que componen, y en que sin duda acreditará haber correspondido por su parte a las loables intenciones de V. E. y V. S. S. ${ }^{18}$.

16 Op. cit. (1991), p. 188

17 Gomis Blanco, A. (1987), «Sessé y la Expedición de Mopox a Cuba». La Real Expedición a Nueva España (1787-1803), pp. 212-216.

18 Archivo Nacional de Cuba (ANC). Junta de Fomento. Legajo 97, n. ${ }^{\circ} 4080$, Folio 56. 


\section{LA REAL EXPEDICIÓN BOTÁNICA A NUEVA ESPAÑA}

Ante esta propuesta, la Junta solicitó al propio Sessé la redacción de unas instrucciones que sirvieran de orientación a Estévez a fin de ejecutar satisfactoriamente su nueva responsabilidad. En noviembre de 1797, Sessé comunicó al Real Consulado de La Habana tales instrucciones mediante las cuales le indicaba a Estévez:

... formar un curso de Botánica, adaptable a las plantas del país, que hayan de demostrarse por exemplo en las lecciones para la más fácil inteligencia de los discípulos ${ }^{19}$.

Para el desarrollo de este curso sugirió también Sessé la formación de herbarios, con su correspondiente clasificación y denominación, para lo cual podría auxiliarse del profesor Boldo, proponiéndole para este fin:

... anotará Ud. en el curso de Botánica que sirve para la enseñanza del Real Jardín Botánico de Madrid las plantas que se pueden adquirir en estas inmediaciones en lugar de las que se citan, hasta que formada la Flora de la Isla resuelva la Junta sacar de ella, e imprimir el curso elemental para esta escuela ${ }^{20}$.

El interés por la conformación de la Flora del país se manifestó constantemente en sus sugerencias:

Pondrá VM el mayor empeño en inquirir los nombres con que se conoce cada planta en este país y lugar en que se cría, para poderlas adquirir con facilidad, siempre que se necesite alguna.

No olvidará Vm expresar al fin de las descripciones los usos que hicieren los naturales de ellas, tanto en la medicina como en la economía, y siempre que las virtudes que se les atribuyan estén confirmadas con competente número de Observaciones, y fundadas en los principios del Arte, convendrá anotar qué puede usarse en lugar de ésta u otra Planta oficinal Europea, que se escasea en nuestras Boticas, o suele hallarse tan deteriorada, que se puede dudar de su eficacia. De manera que si por este medio se lograse formar una Materia vegetal de las plantas de esta Isla sería un

19 Ibidem, fol. 54-60

${ }^{20}$ Ibidem. 
servicio que nunca agradecería a Vm bastante la Junta y el público lograría el beneficio que se ha propuesto con el fomento de la botánica ${ }^{21}$.

Sin duda, estas valiosas indicaciones constituirían un importante instrumento para la Junta y Estévez a fin de llevar a feliz término los objetivos propuestos, en especial la enseñanza de la botánica, priorizándose para ello la recolección de las plantas del país. Para facilitar el trabajo del botánico cubano, Sessé comunicó entre otras cuestiones, en estas propias instrucciones, la propuesta de Estévez como miembro correspondiente de los Jardines de México y de Madrid. A juzgar por todo ello, tanto por parte de la Sección dirigida por Sessé, así como del Real Consulado - que como se ha dejado claro, era el que tenía el potencial económico-, la Cátedra y el Jardín no tardarían en ponerse en práctica, sobre todo por el interés de la Junta en instruir a la juventud en la medicina y cultivar tanto plantas indígenas como exóticas; sin embargo, en parte de estas propias instrucciones se aclaraba:

Aunque por ahora no esté la Junta en proporción de principiar la obra del Jardín, no estará de más colectar toda especie de semilla, y grangearse en las Poblaciones y Haciendas correspondientes a quien pedirlas, siempre que se hubiesen de menester para el fomento del Jardín ${ }^{22}$.

Estos inconvenientes no incidieron de ninguna manera en que se continuará trabajando con vistas a crear más adelante dicho centro, lo cual se evidencia en la comunicación de la Junta dirigida a Sessé donde se expresa:

4... queda este cuerpo en viva expectación de las últimas propuestas que V. M. le ofrece sobre el plan de un jardín en esta ciudad y demás medios de propagar la ciencia Botánica en el país ${ }^{23}$.

21 Ibidem

22 Ibidem, fol. 58-59.

23 Ibidem, fol. 58. 


\section{LA REAL EXPEDICIÓN BOTÁNICA A NUEVA ESPAÑA}

En efecto, entre esas nuevas propuestas, se encontraba el envío a la Junta a principios de 1798 de la copia del Reglamento del Jardín Botánico de México y el Plan de Enseñanza, sugiriendo se le hicieran las modificaciones pertinentes, además de algunas interesantes observaciones que constituyeron algunos años más tarde un valioso recurso para aquéllos a quienes correspondió la construcción y fundación del Jardín habanero, entre las que se encontraba la propuesta que había hecho Sessé del terreno en que se debía ubicar el Jardín y que consistía en:

Sólo resta prevenir en contestación al oficio del 27 de octubre que para facilitar la instrucción a los jóvenes dedicados a las tres ramas de la medicina, recreo a los vecinos de esta capital y adorno a la misma ciudad que son los tres fines que se deben proponer en el establecimiento de un Jardín Botánico, ningún terreno me parece más acomodado que el que media entre el Arsenal y el Barrio de Jesús Maria y Camino de Puerta de Tierra, tanto por su inmediación a la ciudad y paseo, como por la posición y solidez del terreno y la circunstancia de ser el más abrigado de los nortes, especialmente si corre de Oriente a Occidente el edificio que ha de servir de casa para el catedrático, aulas y cuartos para los jardineros; y si se continúa una tapia que cierre el jardín por la parte del norte bastando una decente estaca para asegurarle por los otros tres cos$\operatorname{tados}^{24}$.

Precisó además alguna de las orientaciones ofrecidas a Estévez en cuanto a la organización de las plantas en el Jardín, situación de los árboles que debían dar sombra, construcción de una fuente para facilitar el riego y que además sirviera para adornar el establecimiento, así como detalló cuales eran las piezas más necesarias, lamentando no haber podido reflejar todo ello en un plano, que pretendía trabajar a imitación del aprobado para México.

Así se puede decir que concluía Sessé sus actividades en la Isla, donde compartió su trabajo de investigación con una interesante labor de asesoramiento y orientación, dada su experiencia como Director del Jardín mexicano. Antes de su partida a México manifestó su disposición de continuar colaborando con este proyecto, expresándose en los siguientes términos:

\footnotetext{
${ }^{24}$ Ibidem, fol. 81.
} 


\section{MERCEDES VALERO}

Si desde Madrid, a donde me llama S. M. para dar a luz los trabajos de mis expediciones pudiese contribuir en algo para la realización de este importantísimo proyecto, la $\mathrm{R}$. Junta podrá contar con mis débiles influjos, en inteligencia de que toda ocupación en este particular, lejos de serme molesto, llenará los deseos de mi natural inclinación a la Botánica, y al bien que dicho estudio puede resultar a la humani$\mathrm{dad}^{25}$.

Una vez incorporado Estévez a la Comisión Real de Guantánamo, además del dibujante mexicano Atanasio Echaverría, Sessé y Jaime Senseve se dispusieron a regresar a México, quedando en manos del botánico cubano la responsabilidad de la conformación de la Flora de Cuba y en particular de Estévez al ocurrir en 1799 la muerte de Boldo. A partir de este momento el Conde de Mopox comisionó a Estévez para viajar a Madrid, con la misión de llevar los resultados de la expedición, ocasión que aprovechó el Real Consulado para autorizarlo a iniciar sus estudios de Mineralogía y Química en esta ciudad. A pesar de estos esfuerzos no sería hasta 1824 cuando en realidad se dio comienzo a la enseñanza de la botánica en el Jardín Botánico de la Habana.

Es importante reconocer que la presencia en Cuba de esta Sección de la Expedición Botánica a Nueva España, y en particular de su Director Martín de Sessé, contribuyó a que en un futuro pudiera contar Cuba con un Jardín Botánico, que se caracterizó no sólo por la labor de clasificación y aclimatización de especies, sino también que en cierta medida contribuyó a la institucionalización en el país de la enseñanza de la botánica y su correspondiente aplicación a la medicina, la agricultura y las artes.

25 Ibidem, fol. 82. 